\title{
Human teneurin-1 is a direct target of the homeobox transcription factor EMX2 at a novel alternate promoter
}

\author{
Jan Beckmann ${ }^{1,2 \dagger}$, Antonio Vitobello ${ }^{1,2 \dagger}$, Jacqueline Ferralli' ${ }^{1}$, Daniela Kenzelmann Brož ${ }^{3}$, Filippo M Rijli ${ }^{1,2}$ and \\ Ruth Chiquet-Ehrismann ${ }^{1,2^{*}}$
}

\begin{abstract}
Background: Teneurin-1 is a member of a family of type II transmembrane proteins conserved from C.elegans to vertebrates. Teneurin expression in vertebrates is best studied in mouse and chicken, where the four members teneurin-1 to -4 are predominantly expressed in the developing nervous system in area specific patterns. Based on their distinct, complementary expression a possible function in the establishment of proper connectivity in the brain was postulated. However, the transcription factors contributing to these distinctive expression patterns are largely unknown. Emx2 is a homeobox transcription factor, known to be important for area specification in the developing cortex. A study of Emx2 knock-out mice suggested a role of Emx2 in regulating patterned teneurin expression.
\end{abstract}

Results: 5'RACE of human teneurin-1 revealed new alternative untranslated exons that are conserved in mouse and chicken. Closer analysis of the conserved region around the newly identified transcription start revealed promoter activity that was induced by EMX2. Mutation of a predicted homeobox binding site decreased the promoter activity in different reporter assays in vitro and in vivo in electroporated chick embryos. We show direct in vivo binding of EMX2 to the newly identified promoter element and finally confirm that the endogenous alternate transcript is specifically upregulated by EMX2.

Conclusions: We found that human teneurin-1 is directly regulated by EMX2 at a newly identified and conserved promoter region upstream of the published transcription start site, establishing teneurin-1 as the first human EMX2 target gene. We identify and characterize the EMX2 dependent promoter element of human teneurin-1.

\section{Background}

Many transmembrane proteins mediate cell-cell interactions and thereby regulate key developmental processes. Teneurins are a unique family of type II transmembrane proteins conserved from Drosophila melanogaster and Caenorhabditis elegans to vertebrates, where four paralogues exist called teneurin 1-4 [1]. This protein class was discovered in a screen for the Drosophila homologue of the extracellular matrix protein tenascin-C [2]. Structure and domain architecture are highly conserved across phyla. All proteins of the teneurin family share a large

\footnotetext{
* Correspondence: ruth.chiquet@fmi.ch

† Contributed equally

${ }^{1}$ Friedrich Miescher Institute for Biomedical Research, Novartis Research

Foundation, Maulbeerstrasse 66, CH-4058 Basel, Switzerland

Full list of author information is available at the end of the article
}

extracellular domain with eight tenascin-type EGF-like repeats followed by a region of conserved cysteines and YD repeats [3]. Recently, several publications suggested that the $\mathrm{C}$-terminal parts of the teneurin proteins contain peptides with similarities to corticotrophin-releasing factor (CRF) and might have a function in modulating CRFmediated behavior [4]. All vertebrate teneurins have an $\mathrm{N}$-terminal intracellular domain with two polyproline motifs, EF-hand-like metal ion binding sites and several putative phosphorylation sites. This intracellular domain was shown to be cleaved from the membrane and translocates into the nucleus where it can interact with transcription factors and alter gene expression [5-7].

In C. elegans, RNAi knockdown and deletion of its single teneurin gene (Ten-1) results in a broad range of phenotypes, including defects in axon guidance and neuronal

\section{() Biomed Central}


pathfinding, as well as gonadal disintegration and protrusion of the vulva [8-10]. Drosophila harbors two teneurin genes, Ten-a [2] and Ten-m/Odz [11,12]. Mutations in either of these genes result in embryonic lethality and Ten-a mutants enhance the segmentation phenotype of weak alleles of Ten-m/Odz [13]. It was also shown that teneurin expression is required for the proliferation and cellular identity in the Drosophila eye [14]. Extensive localization studies in mouse [15-17] and chicken [5,18-20] embryos, as well as in rat [21] and zebrafish [22] revealed that the different members of the teneurin protein family are expressed with overlapping patterns by distinct subpopulations of neurons. Experiments in vitro and in vivo showed that the different members of the teneurin family form disulfide-linked dimers [16,23] and promote homophilic cell-cell adhesions and neurite outgrowth $[18,24]$. These functions of the protein are believed to mediate correct pathfinding and area recognition of neurons. This was shown in the teneurin-3 knockdown mouse, which exhibits dramatic changes in the mapping of ipsilateral retinal inputs causing mismatches in binocular mapping. This is associated with major deficits in the performance of visually mediated behavioral tasks [25].

Recent findings suggest an important role for the teneurin protein family in establishing cortical arealization and patterning in the developing embryo. Teneurin2 was found to be expressed in developing limbs, somites and craniofacial mesenchyme in a pattern strikingly similar to that of fibroblast growth factor 8 (Fgf8) and Fgf8 coated beads implanted into chicken limb buds induced ectopic teneurin-2 expression in situ [20]. Furthermore, teneurin-4 transcripts are down regulated, and the expression patterns of teneurins are shifted in the cortices of mice deficient in Emx2 [26]. These findings link the regulation of teneurin expression to Fgf8 and Emx2, two proteins that are part of a complex network of growth and transcription factors regulating arealization of the developing brain, a crucial event regulating sensory perception, the control of our movements and behavior (reviewed in [27]). The best studied protein in this network is Emx2. Emx2 is the vertebrate homologue of the Drosophila empty spiracles (ems) protein, which is involved in the development of the fly head [28]. This protein is a homeobox-containing transcription factor implicated in mouse cerebral cortex development [29]. It is expressed in a graded manner from rostral (low) to caudal (high) [30-33]. Knock-out and overexpression studies of Emx2 showed the function of this transcription factor in establishing the correct size and positioning of cortical areas [reviewed in 34]. Comparing expression analyses of different embryonic stages to the adult for both Emx2 [32,33] and teneurins $[5,7,35]$ showed that areas of Emx2 expression (e.g., the cortical plate, dentate gyrus and the olfactory bulb) strongly correlate with areas of teneurin expression, suggesting a possible role of teneurins in mediating arealization.

The human teneurin- 1 gene resides on the $\times$ chromosome at position Xq25, a locus with low gene density [reviewed in 36]. Beside severe mental retardation, patients suffering from a syndrome mapped to this locus also suffer from motor sensory neuropathy, deafness and severely impaired vision [37-41]. Given the predominant expression in the developing brain and its function in establishing proper connectivity in the brain, teneurin-1 is a potential target gene for causing XLMR.

In order to provide the basis for an investigation of possible deletions and mutations in teneurin-1 of XLMR patients, we decided to delineate the gene locus and determined the transcription start site(s) of human teneurin-1. We identified a novel promoter upstream of the published transcription start, which is conserved in chicken and mice. We show that EMX2 directly binds to and regulates human teneurin-1 expression at this alternate promoter.

\section{Results \\ Identification of alternate transcription start sites of the teneurin-1 gene}

Whereas the expression and localization of the different members of the teneurin protein family are well characterized, promoter regions regulating teneurin gene expression in vertebrates have not yet been studied. To find the transcription start point of human, mouse and chicken teneurin-1 (gene name is ODZ1), we performed 5'-RACE on brain cDNAs of the respective species. We used gene-specific primers derived from the first coding exon and in each case identified two classes of products (Figure 1 and Table 1). The first class ended with the 5'UTR of the published first exon containing the translation start site (as depicted in the genome browser as ODZ1), and the second class included additional noncoding exons. Two additional exons were found in human, three in mouse, and one in chicken teneurin- 1 . All of these exons were between $80 \mathrm{~kb}$ and over $200 \mathrm{~kb}$ distant from the first coding exon. CpG islands were found surrounding the newly identified alternate first exon suggesting promoter activity in this region. Using $4 \mathrm{~kb}$ of sequence surrounding the newly identified first exon of human teneurin-1 to BLAST the mouse genome revealed that this entire region was conserved between species with an overall sequence identity of $58 \%$, and included local sequence identities of over $90 \%$. Based on these findings, we considered that teneurin-1 expression is regulated by two different promoters that are used to differentially regulate teneurin-1 expression. 


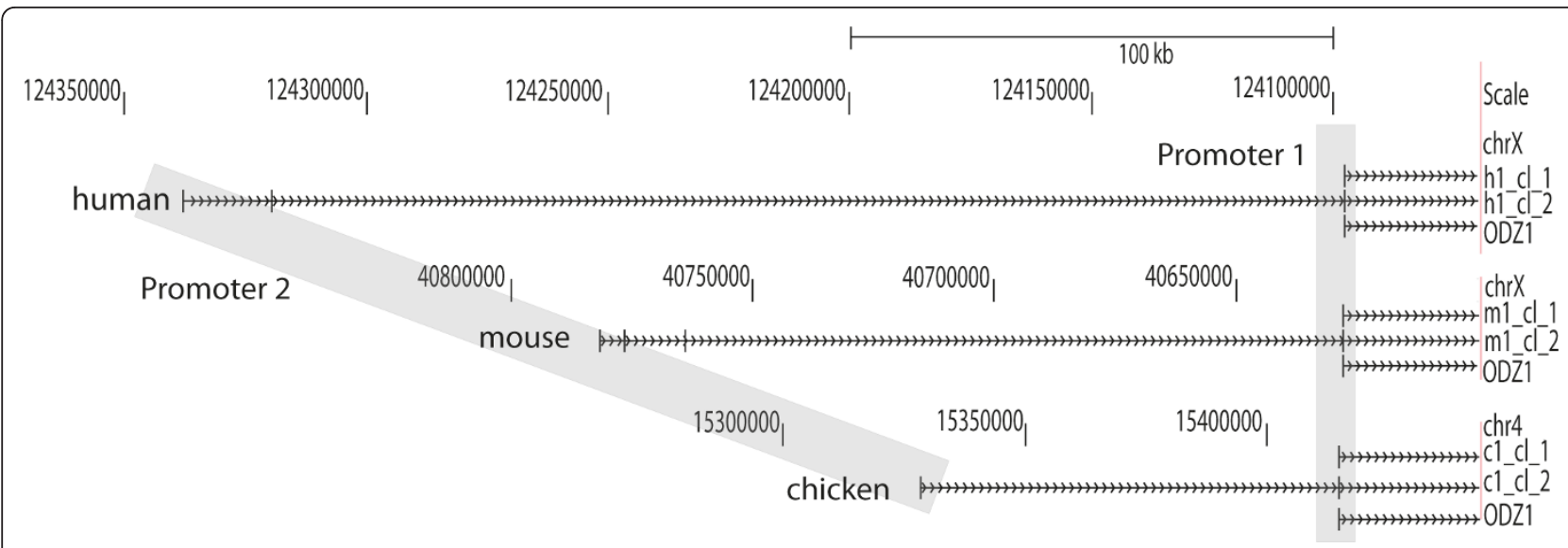

Figure 1 Determination of teneurin-1 transcription start sites. BLAT alignments to the corresponding RefSeq sequences of 2 representative clones per species obtained by $5^{\prime}$ rapid amplification of cDNA ends are shown. The sequences of the clones are given in Table 1. The human clone h1_cl_1, the mouse clone m1_cl_1 and the chicken clone C1_cl_1 start with the annotated first exon containing the ATG translation start, whereas clones h1_cl_2, m1_cl_2 and c1_cl_2 contain up to three further non-coding exons. Based on the presence of two different transcription start sites, two alternate promoters (grey shaded areas) are postulated to control the expression of the two types of transcripts. Promoter 1 resides upstream of the first coding exon, whereas Promoter 2 is located about 100-200 kb upstream depending on the species analyzed.

\section{EMX2 transactivates teneurin-1 promoter reporter constructs in cell culture}

To test whether human teneurin-1 is a direct target gene of EMX2, we set up a reporter gene assay. We obtained a myc-flag-tagged EMX2 expression plasmid to transfect NIH3T3 cells. Recombinant EMX2 could be detected in cell extracts as a $37 \mathrm{kD}$ protein band on Western blots with a FLAG antibody (Figure $2 \mathrm{a}$ ) and the protein accumulated in the nuclei of the cells as shown by immunostaining (Figure 2b). In order to do promoter reporter assays, we cloned a $4 \mathrm{~kb}$ fragment of highly conserved genomic sequence around the published transcription start site, as well as around the newly determined upstream transcription start site of human teneurin-1 into a pSEAP2-basic reporter vector. These promoter reporter constructs were co-transfected with the EMX2 plasmid into HEK293 cells and reporter gene activity was measured (Figure 2c). Interestingly, EMX2 was able to strongly induce reporter gene activity from the newly identified upstream promoter 2 , but not from promoter 1 , which remained unchanged compared to the empty vector control. Previously it was shown that EMX2 binds to a homeobox binding motif in the Wnt-1 promoter [42]. Upon sequence analysis of the promoter 2 construct we found one conserved site with a high score for EMX2 binding, while the promoter 1 construct possessed several high scoring binding sites. This indicates that the mere presence of core sequences of homeobox binding elements is not sufficient per se for the induction by EMX2, but the context may matter as well. To examine whether the homeobox binding motif in the promoter 2 construct contributes to the reporter gene activation upon EMX2 co-transfection, we mutated this motif and measured secreted embryonic alkaline phosphatase (SEAP) reporter gene activity. Indeed, the SEAP activity dropped significantly to $50 \%$ compared to the wild-type construct (Figure 2c).

\section{EMX2 transactivates a teneurin-1 promoter construct in chick embryos electroporated in ovo}

To further prove the promoter activity of the upstream sequence, as well as its dependence on EMX2 expression, we carried out an in ovo reporter gene assay in chick embryos. Upon co-electroporation of the promoter 2-lacZ construct with the EMX2 expression vector in the chick embryo neural tube, lac $Z$ staining was strongly detected in the electroporated area (Figure 3b), whereas no staining was visible with the empty lacZ vector control (data not shown) or upon electroporation with the promoter 2 -lacZ construct alone (Figure $3 \mathrm{~b}$ ). A GFP-expressing construct was always co-electroporated as well and used as a control for the efficiency of electroporation (Figure 3a).

To confirm the influence of the putative EMX2 binding motif on reporter gene activation in vivo, we co-electroporated the mutant promoter 2 -lac Z construct with EMX2 and compared the staining with that of embryos co-electroporated with the wild-type promoter 2-lacZ construct and EMX2. Similar to the cell culture based reporter gene assay (Figure 2), reporter gene activity was also strongly reduced in vivo. Indeed, the vast majority of the embryos co-electroporated with EMX2 and the mutated promoter 2-lac Z construct showed a much fainter lacZ staining than those co-electroporated with 
Table 1 Sequences obtained in 5'RACE (Translation start site in bold and underlined)

\begin{tabular}{|c|c|}
\hline clone name & sequence \\
\hline h1_cl_1 & $\begin{array}{l}\text { GCCTCTACCAAAAGTCAAGCATGAAATGGATCTAG CTTACACCAGTCTTCTGGATGAGAGTGAAG } \\
\text { ATGGAAGAAAACCAAGACAGTCATACAACTCCAGGGAGACCCTGCACGAGTATAACCAGGAGCT } \\
\text { GAGGATGAATACAATAGCCAGAGTAGAAAGAGGAAAGAAGTAGAAAATCTACTCAAGAGAT } \\
\text { GGAATTCTGTGAAACCTCTCACACTCTGTGCTCTGGCTACCAAACAGACATGCACAGCGTTCTCG } \\
\text { GCATGGCTACCATCTAGA }\end{array}$ \\
\hline h1_cl_2 & 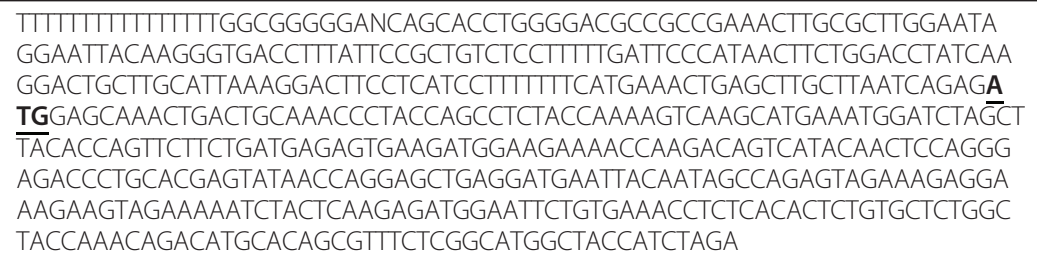 \\
\hline m1_cl_1 & $\begin{array}{l}\text { TाTाTCCACCGCCACCTCCTCCACATGCCTGCACCTGTGCCAGGAAGCCACCTCCTACAGTGGAC } \\
\text { TCTCTACAAAGAAGATCAATGACTACCCGCAGCCAGCCCAGCCCAGCTGCTCCTGCTCCTCCAACC } \\
\text { AGCACACAGGATTCGGTCATCTGCATAACAGCTGGGTCTTGAACAGTAACATACCGCTGGAGAC } \\
\text { CAGGTACATTITATGATTGACCATTCAGCAAAGACTGTITCATTAAAGAACTCCTTATCCTTाT } \\
\text { TTCATGAAACTCAGCTGGCTAAATCAGAGATGGAGCAAACAGACTGCAAACCTAATCAGCCTCTG } \\
\text { TCCAAAGTCAAGCATGTCTAGA }\end{array}$ \\
\hline m1_cl_2 & $\begin{array}{l}\text { TITTCCCGCAGGAACCAGCAAAGACGCCCTAAGTCCAGCGCACTTACAGCACACCAGCAGAGC } \\
\text { TGAGTACCTGGCAAGGAGGCGGGGGACCGCACCTGAGGACATCACTGAAACTTGCGCCTGGACT } \\
\text { AGTCCTCTACTGCCATGGAAACTAGATGGCACAGACAGCGGAGAGTCACTCATTCAGAACAGG } \\
\text { GGCCCCCTIITAATITCATGTCAGCCTGTTGGTCCCTGAAAGTAACTGAAAAGGAATACAAGA } \\
\text { GCGACTITATTCTGTGTAACTTCTCTTCTGGATCTAACAAGGTACATTITATGATTGACCATTCA } \\
\text { GCAAAGACTGTITCATTAAAGAACTTCCTTATCCTIIITCATGAAACTCAGCTTGCTAAATCAGA } \\
\text { GATGGAGCAAACAGACTGCAAACCTTATCAGCCTCTGTCCAAAGTCAAGCATGTCTAGA }\end{array}$ \\
\hline c1_cl_1 & $\begin{array}{l}\text { TITTCCTCATTCCTTAAGGAATTCCAGTTGCTTGTTTCATGATTTGAGCCTATTCAGCCAGA } \\
\text { GATGGAGCAGATGGACTGCAAACCCTACCAGCCACTGTCAAAAGTTAAACATGAAGTGGATCTA } \\
\text { ACNTTACACAAGTTCTTCAGATGAAAGTGAAGATGGCAGAAAGCAAAGGCAATCTTATGACTCA } \\
\text { AGAGAAACTCTGAATGAATATAGCCAAGAGCTAAGACTGAACTACAACAGTCAAGGCAGAAAAA } \\
\text { GAAAAAATACTGACCAATCCACACAAGACATGGAATTCTGTGAGACACCCCACATTCTGTGCTCT } \\
\text { GGCTACCAAACAGATTACATGGTGTGCGGAGCACAGCTACCCACTAGAGGTGGGCTCAGATG } \\
\text { TTGATACTGAAACCGAAGGTGCGCATCACCAGATCATGCCCTGAGGATGTGGATGAGGGGGAT } \\
\text { GAAGTCAGAACACAGCTCCTGTCCGTCAAGCCGGGCAAACTCAGCGTGTCCCTGACTGACACTG } \\
\text { ACCATGAGAGGAAGTCTGATGGGGAGAATGACATGCCGGGGAGCCCACACAACCAGTTCACGTT } \\
\text { TCTAGA }\end{array}$ \\
\hline C1_Cl_2 & 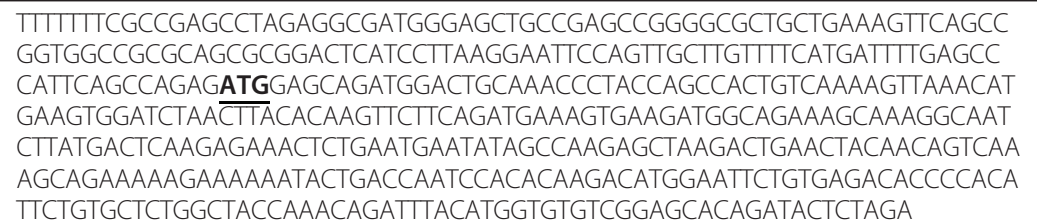 \\
\hline
\end{tabular}

EMX2 and the wild type promoter 2-lacZ construct (Figure $3 \mathrm{~b})$. These findings show that EMX2 is able to induce reporter gene activity at the alternate teneurin-1 promoter and that this activation is greatly dependent on an intact homeobox binding motif.

\section{EMX2 binds a homeobox core element in the alternate teneurin-1 promoter}

To prove that the activation of the construct is due to the direct binding of EMX2 to the homeobox binding motif in the novel upstream promoter, we performed an electrophoretic mobility shift assay (EMSA). Nuclear extracts of HEK293 cells transfected with the EMX2 construct showed a shift of the labeled probe containing the putative homeobox binding site of the upstream promoter, whereas no shift was observed in nuclear extracts of untransfected HEK 293 cells or with a mutated labeled probe (Figure 4a, lanes 1-3). To show the specificity of the binding, the effect of wild-type or mutated unlabeled oligo-nucleotide on the protein/DNA interaction was analyzed. Whereas no shift of the oligo-probe was visible when competing with the unlabeled wildtype oligonucleotide, the shift was still detected in the presence of excess mutant unlabeled oligo-nucleotide (compare lanes 4 and 5). The complex was super-shifted with a c-myc antibody against the tagged EMX2, and indeed the shifted band disappeared (lane 6). This indicates a direct binding of EMX2 to the probe, but due to a high unspecific background the super-shifted band could not be resolved. 


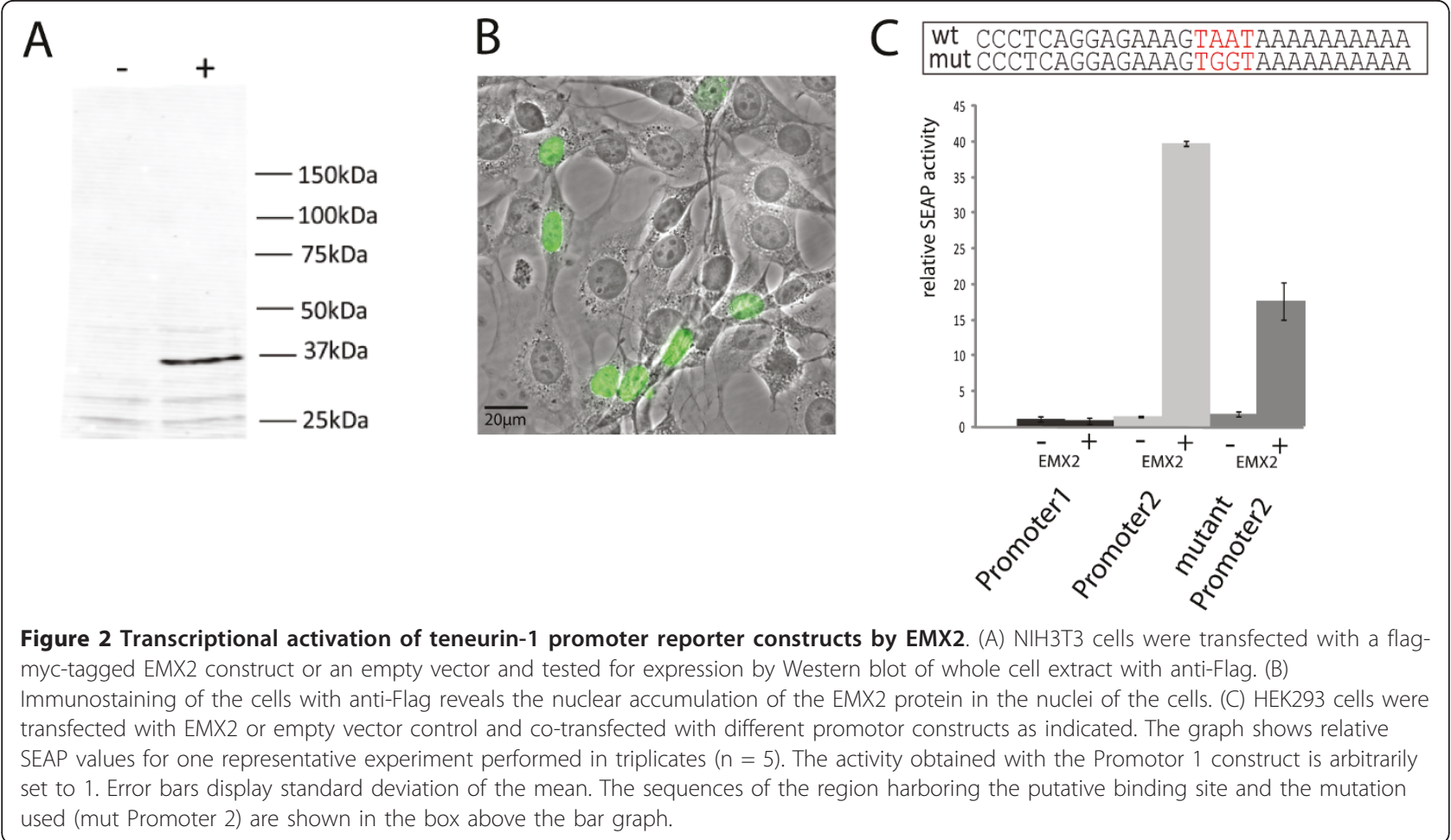

To reduce the unspecific background obtained with the nuclear extract, we tested EMX2 produced by in vitro transcription and translation in the gel shift assay. Whereas no shift of the labeled probe was detected with mock extracts, the same shifted band as with the nuclear extract could be detected with in vitro transcribed and translated EMX2 (Figure 4b, lanes 1 and 2 ), while unspecific background was greatly reduced. The binding of the protein to the probe was successfully competed with an excess of unlabeled wildtype oligonucleotides (Figure 4b, lane 3), whereas no competition was detected for unlabeled mutated oligo-nucleotides (Figure 4b, lane 4). Adding c-myc antibody to the binding reaction resulted in a super-shifted band (Figure 4b, lane 5), indicating a direct binding of EMX2 to the homeobox motif in the alternate teneurin-1 promoter.

To test whether an interaction between EMX2 and the binding site in the teneurin-1 promoter can also occur in vivo without overexpression of the EMX2 protein, we tested nuclear extracts of brains from E12.5 embryos known to express high EMX2 levels in the EMSA assay (Figure 4c). We were able to detect a shift of the band with the embryo extract, which runs lower than the complex of the overexpressed tagged protein in the control (compare Figure 4c, lanes 1,2). We were able to compete the binding to the probe with wildtype unlabeled oligonucleotides, whereas no competition was detected using the unlabeled mutated oligo-nucleotide (Figure 4c, lanes $3-4)$. As a final proof of direct binding of EMX2 to the endogenous teneurin-1 promoter at the homeobox binding site in vivo, we performed chromatin immunoprecipitation (ChIP) in chicken embryos electroporated with the FLAG-myc-tagged EMX2 construct. Electroporations were performed in developing telencephalic regions in order to test the ability of Flag-myc-tagged EMX2 to bind the target region in its physiological cell context. Indeed, we detected specific enrichment of the target region containing the homeobox binding site after ChIP with the anti-FLAG antibody, recognizing the electroporated tagged EMX2 protein compared to a negative control region, which was not the case in control embryos (Figure 4d).

\section{Teneurin-1 expression pattern correlates with that of $E M X 2$ in E14.5 embryos}

To test whether the endogenous teneurin-1 expression pattern overlaps with sites of EMX2 expression in the developing brain, we performed in situ hybridizations with a probe for EMX2, a probe for total teneurin-1 and an additional probe specific for the alternate transcript of teneurin-1 on adjacent sagittal brain sections (Figure 5). The staining for teneurin-1 transcripts showed expression at sites that are in accordance with those reported before for E15.5 embryos [26]. Interestingly, staining with a probe specific for the alternate transcript revealed the same staining pattern as the probe for total teneurin-1, indicating that the long transcripts are indeed expressed at these stages of embryogenesis. We detected a correlation 


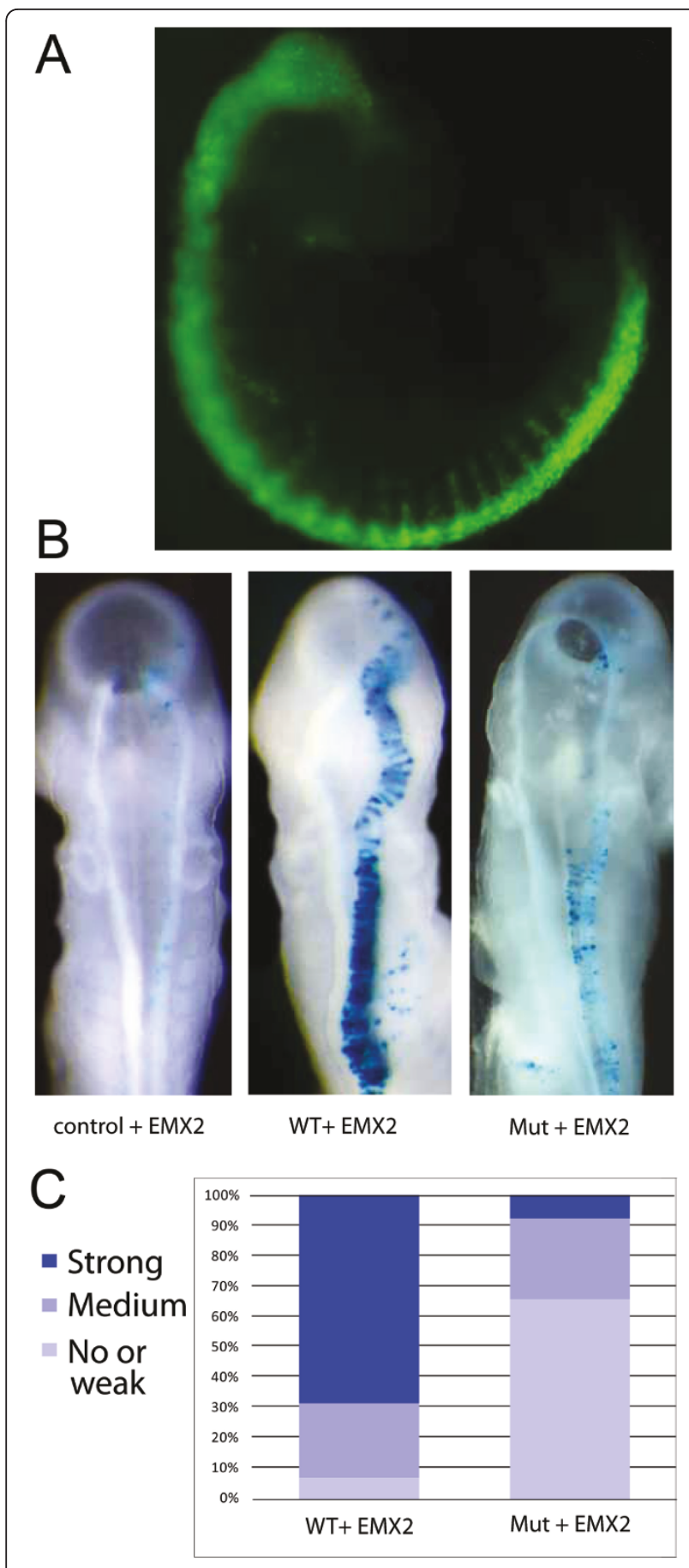

Figure 3 Chicken Embryo Electroporation. (A) Embryos were electroporated at Hamburger and Hamilton stage 10 and collected $24 \mathrm{~h}$ later. A CMV-GFP plasmid was always used as positive control of the electroporation and only embryos showing an expression pattern as shown were kept. Embryos electroporated with betaglobin_LacZ (BGZ40) plasmid alone or in combination with EMX2 in pCMV6-Entry (CMV-EMX2) were used as negative controls (not shown). (B) A 4 kb genomic fragment of the teneurin-1 promoter was cloned into the reporter plasmid beta-globin-LacZ (ten-1BGZ40) and electroporated alone (WT control) or in combination with CMVEMX2 plasmid (WT + EMX2). A mutated version of ten-1BGZ40 lacking a potential EMX2 binding site (mut ten-1BGZ40) was electroporated alone (data not shown) or in combination with CMVEMX2 (Mut + EMX2). (C) Electroporation results are summarized in stacked columns. Data are represented as percentile of the total number of electroporated embryos ( $n=16$ for the WT construct and $n=26$ for the mutated construct) and are classified according to three levels of reporter expression: strong staining, medium staining and no or weak staining.

between the teneurin-1 signals and the EMX2 signal in a caudal high to rostral low gradient. We find teneurin-1 being expressed in the marginal, but not in the ventricular zone of the cortex. Especially good correlations were found in the caudal cortex, olfactory bulb (ob) and hippocampus (hi) (Figure 5).

\section{EMX2 specifically induces the transcription of the alternate transcript}

To test whether EMX2 is able to induce the endogenous teneurin-1 gene from the alternate promoter, we set up a real-time Q-PCR assay. We compared the mRNA expression level for total teneurin-1, as well as for the presence of the exons specific for the alternate transcript in parental HEK293-ECR cells with HEK293-ECR cells stably expressing myc-flag-tagged EMX2 (Figure 6). Indeed, the EMX2 expressing cells showed significantly $(\mathrm{p}<0.01)$ elevated transcript levels of total teneurin-1. Although we generally observed a low expression level for the alternate transcript in our cells, it showed a much higher fold induction upon EMX2 expression than the total mRNA. This is further support for our reporter gene studies on the level of the endogenous gene and represents an independent confirmation that EMX2 specifically acts on the alternate promoter of teneurin-1.

\section{Discussion}

In this work, we characterized the teneurin-1 gene locus and found novel upstream exons which are conserved between species. These new exons expand the size of the Odz1 locus to more than $800 \mathrm{~kb}$, harboring one intron which is more than $200 \mathrm{~kb}$ in size. Genes with large introns have been reported before [43]. A continuous transcription of the entire gene, given a polymerization rate of 3800 nucleotides per minute by RNA polymerase II, would take $3.5 \mathrm{~h}$ [44]. This might add another level of regulation of the defined expression in time and space. Here we show that there are at least two promoters regulating teneurin-1 expression with one alternate promoter upstream of the published transcription start. Only this alternate promoter was inducible by EMX2 in reporter gene assays and cells stably overexpressing EMX2 exhibited an increase of the resulting alternate transcript. A single homeobox binding site seems to be critical for the 
A

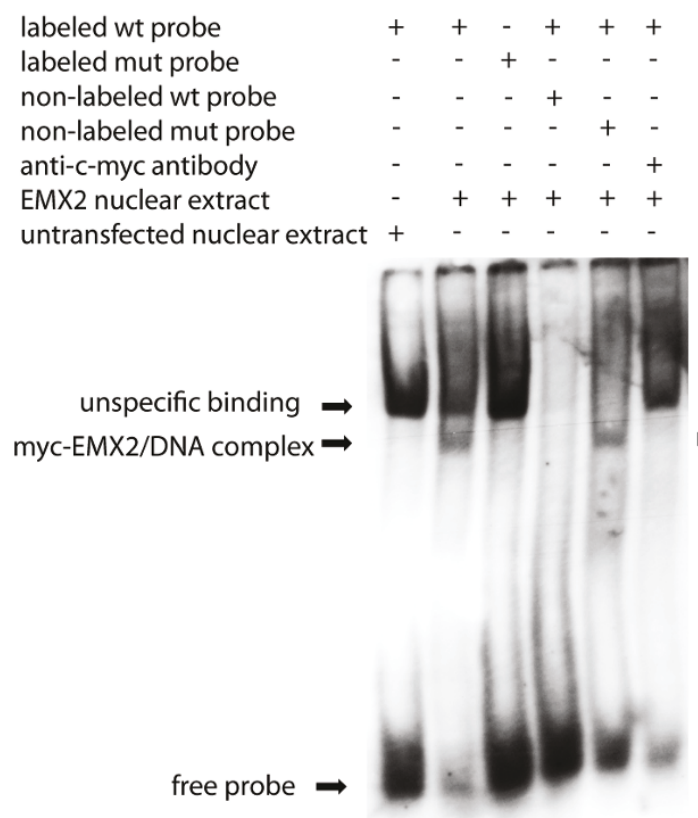

C
B

$$
\begin{array}{lccccc}
\text { labeled wt probe } & + & + & + & + & + \\
\text { non-labeled wt probe } & - & - & + & - & - \\
\text { non-labeled mut probe } & - & - & - & + & - \\
\text { anti-c-myc antibody } & - & - & - & - & + \\
\text { EMX2 in-vitro extract } & - & + & + & + & + \\
\text { untransfected in-vitro extract }+ & - & - & - & -
\end{array}
$$
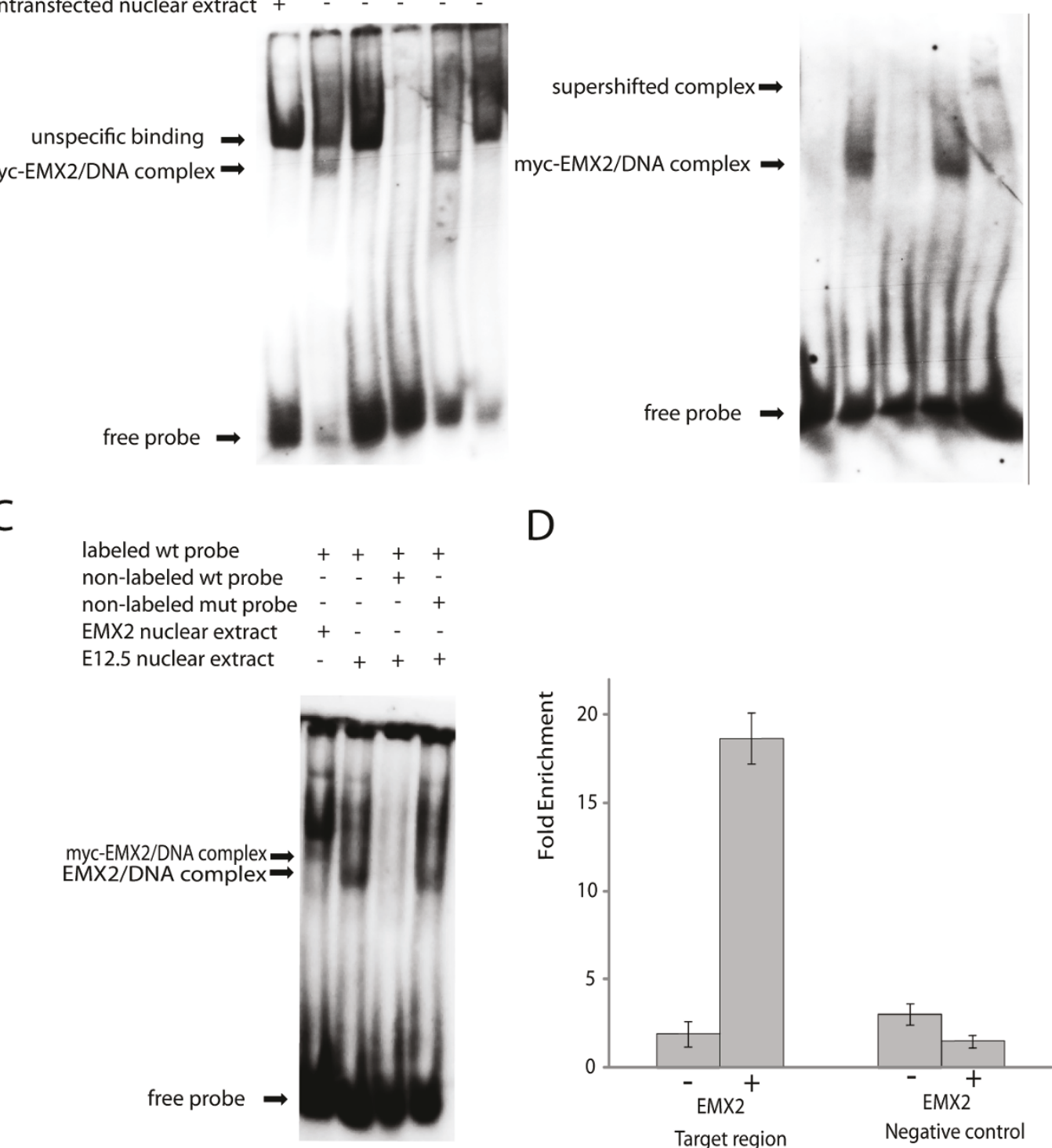

D

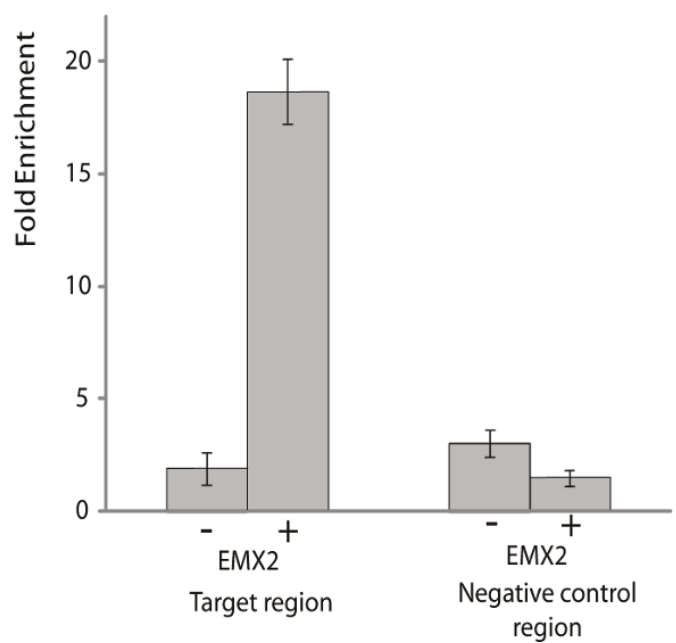

Figure 4 Direct binding of EMX2 to teneurin-1 promoter oligo-nucleotide probes. (A) Electrophoretic Mobility Shift Assays (EMSA) using EMX2 containing nuclear extract or control nuclear extract were performed in the presence or absence of Dig-labeled probe, unlabeled probe for competition, mutated probes and anti-myc antibody as indicated above the lanes. A specific myc-EMX2/DNA complex could be detected as indicated by an arrow. (B) EMSA with in vitro transcribed and translated EMX2 protein or control extracts were analyzed using Dig-labeled wildtype and mutated probes as indicated. Binding to the probe resulted in a myc-EMX2/DNA complex as indicated by an arrow that was competed by unlabeled probe and resulted in a supershifted complex after addition of anti-myc-antibody as indicated. (C) EMSAs with nuclear extracts of E12.5 embryos and nuclear extract of myc-EMX2 overexpressing cells as a control were performed using Dig-labeled wildtype probe. Binding to the probe resulting in a myc-EMX2/DNA complex and an EMX2/DNA complex is indicated by arrows. (D) ChIP of chicken embryos electroporated with flag-myc-tagged EMX2 (+) and control chicken embryos (-). Fold enrichment of the target region, containing the homeobox binding site versus a negative control region from the coding region of the same gene after anti-flag precipitation is shown. Error bars display standard deviation of the mean. 


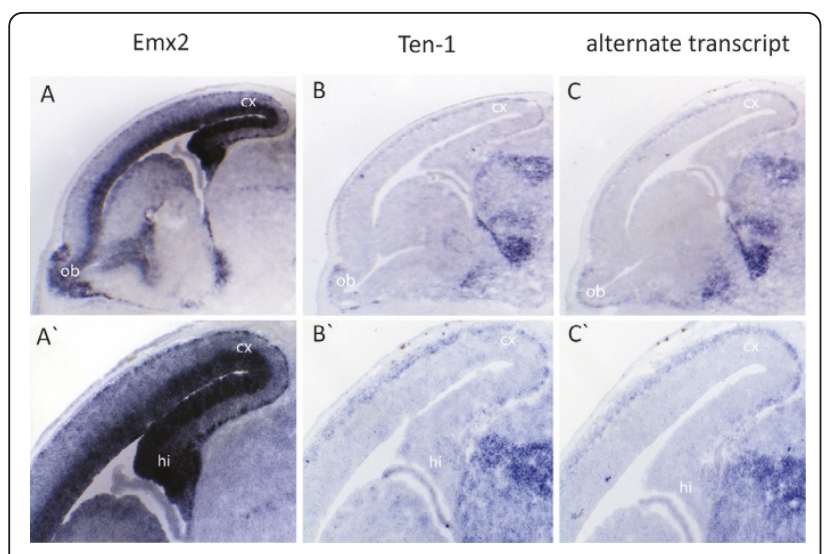

Figure 5 In-situ hybridizations for Teneurin-1 and EMX2 expression on sagittal sections at E14.5 mouse embryos. $\left(A ; A^{\prime}\right)$ Expression of EMX2 in the cortex at higher magnification in $A^{\prime}$. (B; $\left.B^{\prime}\right)$ Expression of total teneurin-1 in an adjacent section. ( $C$; $\left.C^{\prime}\right)$ Expression of the alternate transcript of teneurin-1 in an adjacent section. Ob, olfactory bulb; hi, hippocampus

promoter activity and is bound directly by EMX2, as shown by gel shift assay and ChIP in chicken embryos. Although one has to take into account that the teneurin1 expression, especially in later developmental stages, opposes the expression pattern of EMX2, a direct regulation of teneurin-1 expression by EMX2 is likely to occur at earlier stages. First, we and others [26] showed that

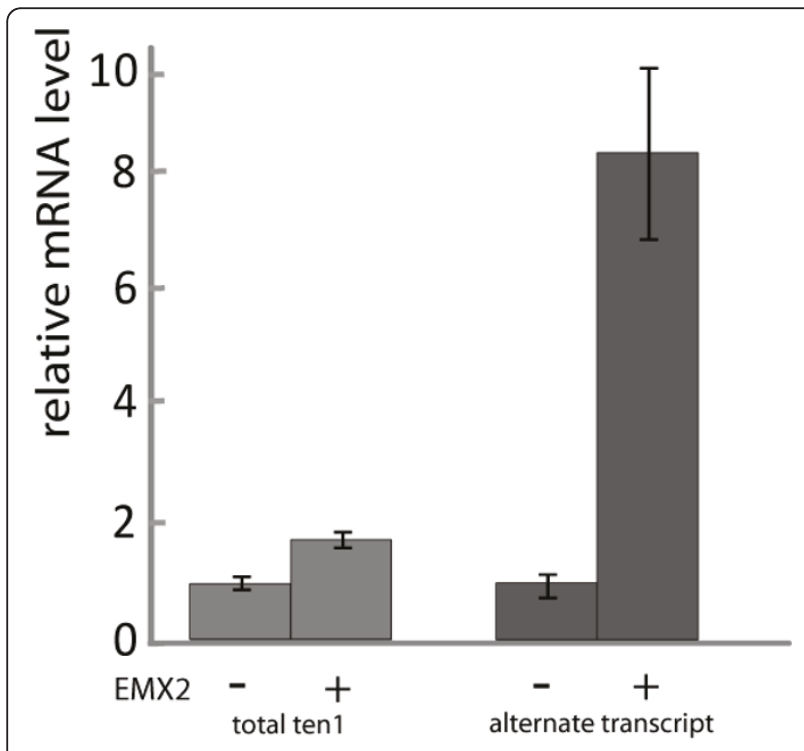

Figure 6 Activation of the alternate transcript by EMX2. RNA was isolated from parental HEK293 cells (-) and HEK293 cells stably expressing EMX2 (+). Teneurin-1 mRNA levels of 3 independent preparations were measured by real-time PCR. The graph shows total teneurin-1 mRNA (total ten1) and mRNA levels under control of the alternate promoter (alternate transcript) relative to GAPDH mRNA values. Values of the parental cells were arbitrarily set to 1. Error bars display standard error of the mean. total teneurin-1 expression, as well as the expression of the alternate transcript, correlates well with EMX2 expression at E14.5. Secondly, the expression of teneurin1 is highly dynamic and its patterned expression and the overall expression level collapses in EMX2-deficient mice [26]. Notably, we found teneurin-1 being expressed in the marginal, but not in the ventricular zone of the cortex. This suggests a possible function of EMX2 in postmitotic neurons via the control of teneurin-1. Based on these findings, it is conceivable that the promoter at the published transcription start is responsible for the basal expression of teneurin-1, whereas the novel promoter is responsible for the graded expression dependent on EMX2. This finding suggests that this promoter region of the teneurin-1 gene is essential in establishing correct patterning of teneurin-1 expression. Although the transcription factors involved in correct patterning and arealization are well known, and their expression patterns are well characterized, very little is known about the downstream mechanisms contributing in establishing proper arealization and pathfinding [reviewed in 45]. A number of reports describe screens to find genes which are differentially expressed within the cortex $[24,46,47]$ or which are potential target genes of differentially expressed transcription factors $[11,26,48-50]$. Interestingly, in both types of approaches members of the teneurin protein family were revealed as differentially expressed genes, supporting the evidence for a role of teneurin in arealization. Lists of potential target genes of the transcription factors involved in arealization, like Emx2 or Pax6, have also been described in knock-out gene expression studies $[26,31,48]$, but indirect effects on transcription cannot be ruled out and interesting targets need to be validated. In this study, we validated teneurin- 1 as the first direct target gene of EMX2 in human. As a transmembrane protein, teneurin-1 is well-suited to convey nuclear signals to the level of cell-cell interactions. However, the molecular mechanisms of how teneurins mediate their proposed function in brain development and patterning of the cortex remain to be elucidated.

Many cases of XLMR have been mapped to Xq25, the locus of the teneurin-1 gene [37-41]. Interestingly, many of these individuals suffer from motor sensory neuropathy [37], and teneurin-1 is predominantly expressed in patterns that relate to anterior sensorimotor areas [26]. Taking into account the regulation of teneurin- 1 by EMX2 at the novel promoter, setting up proper arealization of the developing cortex, and the well established functions of teneurins in correct pathfinding and neurite growth, we consider teneurin-1 as a potential target gene for XLMR. When analyzing patient samples, attention should be given to the newly established promoter region, as mutations or deletions in this area could lead to a shift in expression of teneurin-1 early in the developing brain 
leading to improper connectivity and consequently to XLMR.

\section{Conclusion}

In this work, we show that teneurin-1 expression is regulated by EMX2 at a novel and conserved upstream promoter. We present teneurin-1 as the first direct target gene in humans and characterize the binding site in the newly identified promoter region.

\section{Methods}

\section{Rapid amplification of $5^{\prime}$ complementary DNA ends (5' RACE)}

Total RNA of mouse and chicken brain tissue was purified with QiaShredder and RNA Easy kit (Qiagen, Hombrechtikon, $\mathrm{CH}$ ) according to manufacturer's instructions. Using these RNA extracts and total human adult normal brain RNA (ams Biotechnology, Oxon, UK) 5'RACEs were performed with the 2nd generation 5'/3'RACE kit (Roche Diagnostic, Mannheim, Germany) according to manufacturer's instructions. Nested PCRs with the primer sequences shown in Table 2 were performed. The bands obtained were purified and cloned into vector $\mathrm{pKS}^{+}$and sequenced. The sequences were analyzed using the BLAT algorithm on human genome assembly GRCh37, mouse assembly July 2007 and chicken assembly May 2006 (http://genome.ucsc.edu) [51].

\section{Promoter studies}

The promoter constructs for human teneurin 1 were amplified from human genomic DNA using the Expand High Fidelity system (Roche) with primer hten 1 promoter 1 XhoI fw (all primer sequences are given in Table 2) and hten 1 promoter 1 HindIII rev using the highlighted restriction sites for directional cloning into vector pSEAP2-Basic (Clontech, Mountain View, CA, USA) of the promoter 1 construct. For the hten 1 promoter 2 construct, we used hten 1 promoter 2 NheI fw and hten 1 promoter 2 EcoRI rev using the highlighted restriction sites for directional cloning into the same vector. The promoter 1 construct contains a sequence of just over $2 \mathrm{~kb}$ from nt124097602 to nt124099666 of chromosome $x$ and the promoter 2 construct around $4 \mathrm{~kb}$ from nt124336306 to nt124340205 on chromosome $\times$ of assembly GRCh37. Analysis of the promoter sequences for potential binding sites was done using the JASPAR database (http://jaspar. cgb.ki.se[52]) and the ems matrix. Mutation of the potential homeobox-binding sequence (nt124338584 to nt124338589 on chromosome X) in the promoter 2 was achieved using overlapping PCR with the primer set for hten 1 promoter 2 and mutated promoter $2 \mathrm{fw}$ and rev. HEK293-EBNA cells were plated at $1 \times 10^{5}$ cells per well in six-well plates $18 \mathrm{~h}$ before transfection. Cells were transfected in DMEM containing 0.3\% FCS with Fugene 6
Table 2 Primer sequences

\begin{tabular}{|c|c|}
\hline Primer name & Sequence \\
\hline human RT-PCR & TTAGTGCATGGTCAGGTGAGG \\
\hline mouse RT-PCR & TCTCCCATCTTCACTCTCATCAG \\
\hline chicken RT-PCR & GCTGTGTTCTGACTTCATCC \\
\hline hten PCR1 rev & GTGTCCACATCAGATCCCATCTC \\
\hline hten nested $\mathbf{X b a l}$ rev & TAGTTCTAGAGCACAGGTGCAGGCATGAGG \\
\hline mouse PCR1 rev & CTCCAGCTGGTAGCCATGTCG \\
\hline $\begin{array}{l}\text { mouse nested Xbal } \\
\text { rev }\end{array}$ & TAGTTCTAGATCTGTGTGGTAGCCGGAGCAC \\
\hline chicken PCR1 rev & ATGCGCCACCTTCGGTTTCAG \\
\hline $\begin{array}{l}\text { chicken nested Xbal } \\
\text { rev }\end{array}$ & TAGTTCTAGAGTAGCTGTGCTCCGACACACC \\
\hline $\begin{array}{l}\text { oligo dT anchor } \\
\text { primer }\end{array}$ & GACCACGCGTATCGATGTCGACTIITIITाTाTाTाII \\
\hline $\begin{array}{l}\text { hten1 promotor } 1 \\
\text { Xhol fw }\end{array}$ & ACTACTCGAGCAAGACCCATGCTGAAGCT \\
\hline $\begin{array}{l}\text { hten1 promotor } 1 \\
\text { HindIII rev }\end{array}$ & ACTAAAGCTTCTCTGATTAAGCAAGCTCAGTTTC \\
\hline $\begin{array}{l}\text { hten } 1 \text { promoter } 2 \\
\text { Nhel fw }\end{array}$ & ACTAGCTAGCCCCCTAGAGTGTTCAGCTCT \\
\hline $\begin{array}{l}\text { hten1 promoter } 2 \\
\text { EcoRI rev }\end{array}$ & ACTAGAATTCGGGCCACCTCAAAAACACCTCC \\
\hline $\begin{array}{l}\text { mutate promoter } 2 \\
\text { fw }\end{array}$ & CCACCCCTCACCCTCAGGAGAAAGTGGTTAAA \\
\hline $\begin{array}{l}\text { mutate promoter } 2 \\
\text { rev }\end{array}$ & TTAACCACTTTCTCCTGAGGGTGAGGGGTGG \\
\hline total ten $1 \mathrm{qPCR}$ fw & GCATAGTTCCTGTTTGTCCA \\
\hline total ten $1 \mathrm{qPCR}$ rev & TCTGCACATCTTGAGTAGAC \\
\hline alt exon qPCR fw & GCTTGGAATAGGAATTACAAGG \\
\hline alt exon qPCR rev & GAAGTCCTITAATGCAAGCAG \\
\hline hGAPDH qPCR fw & GGAGTCAACGGATTTGGTC \\
\hline hGAPDH qPCR rev & AAACCATGTAGTTGAGGTC \\
\hline ChIP target region fw & TTCAGCTTCCTCGTTCTTCG \\
\hline ChIP target region rev & GGTGGTTACAACCGCCTTT \\
\hline $\begin{array}{l}\text { ChlP negative control } \\
\mathrm{fw}\end{array}$ & AGATTCCTGTGAGCCCTGCT \\
\hline $\begin{array}{l}\text { ChIP negative control } \\
\text { rev }\end{array}$ & TCCAACAACTCATGCAATGG \\
\hline
\end{tabular}

Transfection reagent (Roche) using $1 \mu \mathrm{g}$ promoter construct DNA and co-transfected with either empty $1 \mu \mathrm{g}$ pcDNA3 or flag- and myc-tagged EMX2 in pCMV-Entry (OriGene, Rockville, MD, USA) as indicated in the Result section. Twenty-Four hours after transfection, the medium was collected and SEAP reporter gene activity was measured and normalized for the co-transfected plasmid pGL3, expressing firefly luciferase (Promega, Madison, WI, USA) as previously described [53].

\section{Real-time Q-PCR}

HEK293-ECR cells were transfected as described before with the flag-myc-tagged EMX2 construct in pCMV and cells were selected for stably expressing clones with G418 (Roche) for 2 weeks. Clones were pooled and expression of the construct was tested by Western blot 
(data not shown). From these cells and untransfected HEK293-ECR cells RNA was isolated with QiaShredder and the RNA Easy kit (Qiagen) following the manufacturer's protocol. From this preparation, cDNA was generated using the Superscript III (Invitrogen) polymerase and random primers following the standard protocol. Real-time Q-PCR was performed on these samples with teneurin-1 specific primers and normalized to GAPDH values (sequences Table 2) using SYBR QPCR Supermix with ROX (Invitrogen) on an AbiPrism 7000 system. Three independent experiments were performed and the averaged results are shown and p-values were calculated using the one-way ANOVA.

\section{In ovo electroporation}

For reporter assay experiments, chicken eggs were incubated in a humidified chamber at $38^{\circ} \mathrm{gC}$ and DNA constructs were injected into the lumen of the neural tube of stage Hamburger Hamilton (HH) 10-12 embryos. Construct concentrations were: $1 \mu \mathrm{g} / \mu \mathrm{l}$ lacZ reporter construct (BGZ40; [54]), $1 \mu \mathrm{g} / \mu \mathrm{l}$ EMX2 expression vector, and $0.2 \mu \mathrm{g} / \mu \mathrm{l}$ co-injected EGFP in $\mathrm{pCMV}$ as positive control of electroporated cells. Embryos were harvested 24 hours after electroporation and processed for $\beta$-galactosidase staining. For EMX2 overexpression, $1 \mu \mathrm{g} / \mu \mathrm{l}$ of Myc/FLAG-tagged EMX2 expression vector and $0.2 \mu \mathrm{g} / \mu \mathrm{l}$ of $\mathrm{pCMV-EGFP}$ construct were coinjected into the lumen of forebrain of stage $\mathrm{HH} 14$ embryos. Positive tissues ( $n=20$ brains) were collected 72 hours after electoporation and immediately processed for chromatin cross-linking. As negative control, the same amount of unelectroporated tissue was collected and processed for ChIP experiments. Electroporations were performed as described previously using a square wave electroporator [54].

\section{Chromatin immunoprecipitation Assay}

Brains were chopped and then cross-linked in 1\% Formaldehyde (F8775, Sigma) for 10 minutes at room temperature. Cross-linking was stopped in $125 \mathrm{mM}$ Glycine for 5 minutes and the material was washed three times in ice cold PBS containing EDTA-free Protease Inhibitor Cocktail (Complete, 04693132001, Roche). DNA shearing was performed in lysis buffer $(50 \mathrm{mMTris}-\mathrm{HCl}$ pH8.0, $10 \mathrm{mM}$ EDTA, 1\%SDS, $1 \times$ Protease Inhibitor Cocktail) using the following parameters: 20 cycles of 30 seconds ON/30 seconds OFF (Diagenode bioruptor sonicator, high power setting).

Chromatin immunoprecipitation was performed by using Dynabeads protein G (100.04D, Invitrogen) as described elsewhere [55]. The following antibodies were used: Mouse monoclonal anti-FLAG M2 (F1804, Sigma), Mouse control IgG (AB18413, Abcam).

\section{Electrophoretic Mobility Gel Shift Assay (EMSA)}

EMX2 binding to the promoter construct was examined by Electrophoretic Mobility Gel Shift Assay (EMSA) using DIG-labeled double-stranded oligo-nucleotides (5'CAGGAGAAAGTAATTAAAAAA3' or with mutated binding site 5'CAGGAGAAAGTGGTTAAAAAA3', putative binding site underlined). For probe preparation, $5 \mu \mathrm{g}$ of sense and anti-sense oligo-nucleotides were diluted in $90 \mu \mathrm{l} \mathrm{TE}$ buffer, incubated for $10 \mathrm{~min}$ at $95^{\circ} \mathrm{C}$ and cooled down for $30 \mathrm{~min}$ at room temperature for annealing. DIG-labeling of the probes was achieved using the DIG Gel Shift Kit, $2^{\text {nd }}$ Generation (Roche) according to the manufacturer's instructions. For the gel shift assay, nuclear extracts from stably EMX2 expressing HEK293 cells, in-vitro translated extracts or nuclear extracts of E12.5 embryo brains containing $20 \mu \mathrm{g}$ of total protein were incubated with $4 \mu$ l of $5 \times$ binding buffer of the Gel Shift Kit, $1 \mu \mathrm{g}$ double-stranded poly $(\mathrm{dIdC})$ and $0.1 \mu \mathrm{g}$ poly-L-lysine in a $19 \mu \mathrm{l}$ reaction mix. For the competition assay, unlabeled wild-type or mutant annealed oligo-nucleotide were added with a 150 -fold excess. This mix was incubated for $20 \mathrm{~min}$ at room temperature. Afterwards, $1 \mu \mathrm{l}$ of labeled probe was added and the mix was incubated for another $20 \mathrm{~min}$ at $30^{\circ} \mathrm{C}$. For supershifts, $1 \mu \mathrm{l}$ of c-myc antibody (Sigma) was added after $10 \mathrm{~min}$ incubation with the labeled probe. Following another $10 \mathrm{~min}$ of incubation, the reaction mix was loaded onto a precast 6\% DNA retardation gel (Invitrogen, Carlsbad, CA, USA), which was pre-run in $0.5 \times \mathrm{TBE}$ for $20 \mathrm{~min}$ at $80 \mathrm{~V}$ and $4^{\circ} \mathrm{C}$. The gel was run for $1.5 \mathrm{~h}$ at $80 \mathrm{~V}$ and $4^{\circ} \mathrm{C}$. After separation, the complexes were blotted on a positively charged nylon membrane in $0.5 \times \mathrm{TBE}$ for $45 \mathrm{~min}$ at $280 \mathrm{~mA}$ and DIG detection was performed as described in the manufacturer's instructions.

\section{In-vitro transcription and translation of EMX2}

In-vitro transcription and translation of EMX2 was achieved using the TNT $^{\circledR}$ Coupled Reticulocyte Lysate System (Promega). $25 \mu \mathrm{l}$ of $\mathrm{TNT}^{\circledR}$ rabbit reticulocyte lysate, $2 \mu \mathrm{TNT}^{\circledR}$ reaction buffer, $1 \mu \mathrm{l} \mathrm{TNT}^{\circledR}$ T7 RNA polymerase, $0.5 \mu \mathrm{l}$ of each Amino Acid mixture without Leucine and without Methionine and $1 \mu \mathrm{g}$ of EMX2pCMV-Entry were mixed in a $50 \mu$ reaction mix and incubated for $90 \mathrm{~min}$ at $30^{\circ} \mathrm{C}$, quick frozen in dry ice/ ethanol and stored at $-80^{\circ} \mathrm{C}$ until used in EMSA.

\section{In-situ hybridization}

In-situ hybridizations on sections were performed as previously described [56]. The following RNA probes were used: For EMX2 we used the entire CDS of EMX2 (NM_010132.2), for total teneurin-1 we used the probe previously published [26] and for the probe specific for 
the alternate transcript we used the sequence described in Table 1 (m1_cl_2) plus the first $100 \mathrm{bp}$ of the CDS of mouse teneurin-1 (NM_011855.3).

\author{
Abbreviations \\ XLMR: X-linked mental retardation; hten1: human teneurin-1; EMSA: \\ Electrophoretic Mobility Shift Assays; RACE: rapid amplification of CDNA ends; \\ CRF: corticotrophin-releasing factor; SEAP: secreted embryonic alkaline \\ phosphatase; ChIP: Chromatin Immunoprecipitation
}

\section{Acknowledgements}

We thank Hans-Rudolf Hotz for the help with the UCSC genome browser, Richard P. Tucker for critical reading of the manuscript and Jean-François Spetz for providing the mouse embryos. This work was supported by the Novartis Research Foundation.

\section{Author details}

'Friedrich Miescher Institute for Biomedical Research, Novartis Research Foundation, Maulbeerstrasse 66, CH-4058 Basel, Switzerland. ${ }^{2}$ University of Basel, Faculty of Science, Basel, Switzerland. ${ }^{3}$ Current Address: Department of Radiation Oncology, Division of Radiation and Cancer Biology, Stanford University School of Medicine, Stanford, CA 94305, USA.

\section{Authors' contributions}

JB prepared all constructs, participated in the 5'RACE, performed sequence alignments, EMSA and QPCR and prepared the first draft of the manuscript. AV performed the chicken electroporation and the ChIP experiments as well as the mouse in-situ hybridization. JF performed the SEAP assay and validated EMX2 expression. DKB performed the 5'RACE in chicken and mouse. FMR participated in the planning and discussion of the experiments. RCE participated in the planning and discussion of the experiments, writing the paper and preparation of the figures. All authors read and approved the final manuscript.

Received: 27 September 2010 Accepted: 8 June 2011

Published: 8 June 2011

\section{References}

1. Tucker RP, Kenzelmann D, Trzebiatowska A, Chiquet-Ehrismann R: Teneurins: Transmembrane proteins with fundamental roles in development. The International Journal of Biochemistry \& Cell Biology 2007, 39:292-297.

2. Baumgartner $S$, Chiquet-Ehrismann R: Tena, a Drosophila gene related to tenascin, shows selective transcript localization. Mechanisms of Development 1993, 165-176.

3. Minet AD, Chiquet-Ehrismann R: Phylogenetic analysis of teneurin genes and comparison to the rearrangement hot spot elements of $E$. coli. Gene 2000, 257:87-97.

4. Lovejoy DA, Rotzinger S, Barsyte-Lovejoy D: Evolution of Complementary Peptide Systems. Annals of the New York Academy of Sciences 2009, 1163:215-220

5. Kenzelmann D, Chiquet-Ehrismann R, Leachman NT, Tucker RP: Teneurin-1 is expressed in interconnected regions of the developing brain and is processed in vivo. BMC Developmental Biology 2008, 8:30.

6. Nunes SM, Ferralli J, Choi K, Brown-Luedi M, Minet AD, ChiquetEhrismann R: The intracellular domain of teneurin-1 interacts with MBD1 and CAP/ponsin resulting in subcellular codistribution and translocation to the nuclear matrix. Experimental Cell Research 2005, 305:122-32.

7. Bagutti C, Forro G, Ferralli J, Rubin B, Chiquet-Ehrismann R: The intracellular domain of teneurin-2 has a nuclear function and represses zic-1mediated transcription. Journal of Cell Science 2003, 116:2957-66.

8. Drabikowski K, Trzebiatowska A, Chiquet-Ehrismann R: ten-1, an essential gene for germ cell development, epidermal morphogenesis, gonad migration, and neuronal pathfinding in Caenorhabditis elegans. Developmental Biology 2005, 282:27-38.

9. Trzebiatowska A, Topf U, Sauder U, Drabikowski K, Chiquet-Ehrismann R: Caenorhabditis elegans teneurin, ten-1, is required for gonadal and pharyngeal basement membrane integrity and acts redundantly with integrin ina-1 and dystroglycan dgn-1. Molecular Biology of the Cell 2008, 19:3898-908.

10. Mörck C, Vivekanand V, Jafari G, Pilon M: C. elegans ten-1 is synthetic lethal with mutations in cytoskeleton regulators, and enhances many axon guidance defective mutants. BMC Developmental Biology 2010, 10:55.

11. Baumgartner S, Martin D, Hagios C, Chiquet-Ehrismann R: Ten $(m)$, a Drosophila gene related to Tenascin, is a new pair-rule gene. EMBO Journal 1994, 13:3728-3740.

12. Levine A, Bashan-Ahrend A, Budai-Hadrian O, Gartenberg D, Menasherow S, Wides R: odd Oz: A novel Drosophila pair rule gene. Cell 1994, 77:587-598.

13. Rakovitsky N, Buganim Y, Swissa T, Kinel-Tahan Y, Brenner S, Cohen MA, Levine A, Wides R: Drosophila Ten-a is a maternal pair-rule and patterning gene. Mechanisms of Development 2007, 124:911-924.

14. Kinel-Tahan Y, Weiss H, Dgany O, Levine A, Wides R: Drosophila odz gene is required for multiple cell types in the compound retina. Developmental Dynamics 2007, 236:2541-2554.

15. Ben-Zur T, Feige E, Motro B, Wides R: The Mammalian Odz Gene Family: Homologs of a Drosophila Pair-Rule Gene with Expression Implying Distinct yet Overlapping Developmental Roles. Developmental Biology 2000, 217:107-120.

16. Oohashi T, Zhou X-H, Feng K, Richter B, Morgelin M, Perez MT, Su W-D, Chiquet-Ehrismann R, Rauch U, Fassler R: Mouse Ten-m/Odz Is a New Family of Dimeric Type II Transmembrane Proteins Expressed in Many Tissues. Journal of Cell Biology 1999, 145:563-577.

17. Zhou X-H, Brandau O, Feng K, Oohashi T, Ninomiya Y, Rauch U, Fässler R: The murine Ten-m/Odz genes show distinct but overlapping expression patterns during development and in adult brain. Gene Expression Patterns 2003, 3:397-405.

18. Rubin BP, Tucker RP, Brown-Luedi M, Martin D, Chiquet-Ehrismann R: Teneurin 2 is expressed by the neurons of the thalamofugal visual system in situ and promotes homophilic cell-cell adhesion in vitro. Development 2002, 129:4697-705.

19. Tucker RP, Martin D, Kos R, Chiquet-Ehrismann R: The expression of teneurin-4 in the avian embryo. Mechanisms of Development 2000, 98:187-91.

20. Tucker RP, Chiquet-Ehrismann R, Chevron MP, Martin D, Hall RJ, Rubin BP: Teneurin- 2 is expressed in tissues that regulate limb and somite pattern formation and is induced in vitro and in situ by FGF8. Developmental Dynamics 2001, 220:27-39.

21. Otaki JM, Firestein S: Neurestin: Putative Transmembrane Molecule Implicated in Neuronal Development. Developmental Biology 1999, 212:165-181.

22. Mieda M, Kikuchi Y, Hirate Y, Aoki M, Okamoto H: Compartmentalized expression of zebrafish ten-m3 and ten-m4, homologues of the Drosophila tenm/odd $\mathrm{Oz}$ gene, in the central nervous system. Mechanisms of Development 1999, 87:223-227.

23. Feng $K$, Zhou $X-H$, Oohashi $T$, Märgelin $M$, Lustig A, Hirakawa $S$, Ninomiya $Y$, Engel Jr, Rauch U, Fässler R: All Four Members of the Ten-m/Odz Family of Transmembrane Proteins Form Dimers. Journal of Biological Chemistry 2002, 277:26128-26135.

24. Leamey CA, Glendining KA, Kreiman G, Kang N-D, Wang KH, Fassler R, Sawatari A, Tonegawa S, Sur M: Differential Gene Expression between Sensory Neocortical Areas: Potential Roles for Ten_m3 and Bcl6 in Patterning Visual and Somatosensory Pathways. Cerebral Cortex 2008, 18:53-66.

25. Leamey CA, Merlin S, Lattouf P, Sawatari A, Zhou X, Demel N, Glendining KA, Oohashi T, Sur M, Fässler R: Ten_m3 Regulates Eye-Specific Patterning in the Mammalian Visual Pathway and Is Required for Binocular Vision. PLoS Biology 2007, 5:e241.

26. Li H, Bishop KM, O'Leary DD: Potential target genes of EMX2 include Odz/ Ten-M and other gene families with implications for cortical patterning. Molecular and Cellular Neuroscience 2006, 33:136-49.

27. Sansom SN, Livesey FJ: Gradients in the brain: the control of the development of form and function in the cerebral cortex. Cold Spring Harb Perspect Biol 2009, 1:a002519.

28. Dalton $D$, Chadwick R, McGinnis W: Expression and embryonic function of empty spiracles: a Drosophila homeo box gene with two patterning functions on the anterior-posterior axis of the embryo. Genes \& Development 1989, 3:1940-1956.

29. Simeone A, Gulisano M, Acampora D, Stornaiuolo A, Rambaldi M, Boncinelli E: Two vertebrate homeobox genes related to the Drosophila 
empty spiracles gene are expressed in the embryonic cerebral cortex. EMBO Journal 1992, 11:2541-2550.

30. Fukuchi-Shimogori T, Grove EA: Emx2 patterns the neocortex by regulating FGF positional signaling. Nature Neuroscience 2003, 6:825-831.

31. Bishop KM, Goudreau G, O'Leary DDM: Regulation of Area Identity in the Mammalian Neocortex by Emx2 and Pax6. Science 2000, 288:344-349.

32. Gulisano M, Broccoli V, Pardini C, Boncinelli E: Emx1 and Emx2 show different patterns of expression during proliferation and differentiation of the developing cerebral cortex in the mouse. European Journal of Neuroscience 1996, 8:1037-1050

33. Mallamaci A, lannone R, Briata P, Pintonello L, Mercurio S, Boncinelli E, Corte G: EMX2 protein in the developing mouse brain and olfactory area. Mechanisms of Development 1998, 77:165-172.

34. O'Leary DDM, Chou S-J, Sahara S: Area Patterning of the Mammalian Cortex. Neuron 2007, 56:252-269.

35. Otaki JM, Firestein S: Segregated expression of neurestin in the developing olfactory bulb. Neuroreport 1999, 10:2677-2680.

36. Minet AD, Rubin BP, Tucker RP, Baumgartner S, Chiquet-Ehrismann R. Teneurin-1, a vertebrate homologue of the Drosophila pair-rule gene ten- $\mathrm{m}$, is a neuronal protein with a novel type of heparin-binding domain. Journal of Cell Science 1999, 112(Pt 12):2019-32.

37. Malmgren $H$, Sundvall M, Dahl N, Gustavson KH, Anneren G, Wadelius C, Steenbondeson ML, Pettersson U: Linkage maping of a severe X-linked mental-retardation syndrome. American Journal of Human Genetics 1993, 52:1046-1052.

38. Gustavson KH, Anneren G, Malmgren H, Dahl N, Ljunggren CG, Backman H: New X-linked syndrome with severe mental retardation, severely impaired vision, severe hearing defect, epileptic seizures, spasticity, restricted joint mobility and early death. American Journal of Medical Genetics 1993, 45:654-658.

39. Cabezas DA, Slaugh R, Abidi F, Arena JF, Stevenson RE, Schwartz CE, Lubs HA: A new $X$ linked mental retardation (XLMR) syndrome with short stature, small testes, muscle wasting, and tremor localises to Xq24-q25. Journal of Medical Genetics 2000, 37:663-668

40. Martínez F, Martínez-Garay I, Oltra S, Moltó MD, Orellana C, Monfort S, Prieto F, Tejada I: Localization of MRX82: A new nonsyndromic X-linked mental retardation locus to Xq24-q25 in a Basque family. American Journal of Medical Genetics 2004, 131A: 174-178.

41. Vitale E, Specchia C, Devoto M, Angius A, Rong S, Rocchi M, Schwalb M, Demelas L, Paglietti D, Manca S, et al: Novel X-linked mental retardation syndrome with short stature maps to Xq24. American Journal of Medical Genetics 2001, 103:1-8.

42. Iler N, Rowitch DH, Echelard Y, McMahon AP, Abate-Shen C: A single homeodomain binding site restricts spatial expression of Wnt-1 in the developing brain. Mechanisms of Development 1995, 53:87-96.

43. Shepard S, McCreary M, Fedorov A: The Peculiarities of Large Intron Splicing in Animals. PLOS ONE 2009, 4:e7853.

44. Singh J, Padgett RA: Rates of in situ transcription and splicing in large human genes. Nat Struct Mol Biol 2009, 16:1128-1133.

45. O'Leary DDM, Sahara S: Genetic regulation of arealization of the neocortex. Current Opinion in Neurobiology 2008, 18:90-100

46. Funatsu N, Inoue T, Nakamura S: Gene Expression Analysis of the Late Embryonic Mouse Cerebral Cortex Using DNA Microarray: Identification of Several Region- and Layer-specific Genes. Cereb Cortex 2004, 14:1031-1044.

47. Mühlfriedel S, Kirsch F, Gruss P, Chowdhury K, Stoykova A: Novel genes differentially expressed in cortical regions during late neurogenesis. European Journal of Neuroscience 2007, 26:33-50.

48. Gangemi RMR, Daga A, Muzio L, Marubbi D, Cocozza S, Perera M, Verardo S, Bordo D, Griffero F, Capra MC, et al: Effects of Em×2 inactivation on the gene expression profile of neural precursors. European Journal of Neuroscience 2006, 23:325-334.

49. Holm PC, Mader MT, Haubst N, Wizenmann A, Sigvardsson M, Götz M: Loss- and gain-of-function analyses reveal targets of Pax6 in the developing mouse telencephalon. Molecular and Cellular Neuroscience 2007, 34:99-119.

50. Numayama-Tsuruta K, Arai Y, Takahashi M, Sasaki-Hoshino M, Funatsu N, Nakamura S, Osumi N: Downstream genes of Pax6 revealed by comprehensive transcriptome profiling in the developing rat hindbrain. BMC Developmental Biology 2005, 10:6.
51. Kent WJ: BLAT - The BLAST-Like Alignment Tool. Genome Research 2002, 12:656-664.

52. Bryne JC, Valen E, Tang M-HE, Marstrand T, Winther O, Piedade I da, Krogh A, Lenhard B, Sandelin A: JASPAR, the open access database of transcription factor-binding profiles: new content and tools in the 2008 update. Nucl Acids Res 2008, 36:D102-106.

53. Degen M, Goulet S, Ferralli J, Roth M, Tamm M, Chiquet-Ehrismann R: Opposite effect of fluticasone and salmeterol on fibronectin and tenascin-C expression in primary human lung fibroblasts. Clinical \& Experimental Allergy 2009, 39:688-699.

54. Itasaki N, Bel-Vialar S, Krumlauf R: 'Shocking' developments in chick embryology: electroporation and in ovo gene expression. Nature Cell Biology 1999, 1:E203-E207.

55. Vitobello A, Ferretti E, Lampe X, Vilain N, Ducret S, Ori M, Spetz J-F, Selleri L, Rijli M Filippo: Hox and Pbx Factors Control Retinoic Acid Synthesis during Hindbrain Segmentation. Developmental Cell 20:469-482.

56. Minoux M, Antonarakis GS, Kmita M, Duboule D, Rijli FM: Rostral and caudal pharyngeal arches share a common neural crest ground pattern. Development 2009, 136:637-645.

doi:10.1186/1471-213X-11-35

Cite this article as: Beckmann et al: Human teneurin-1 is a direct target of the homeobox transcription factor EMX2 at a novel alternate promoter. BMC Developmental Biology 2011 11:35.

\section{Submit your next manuscript to BioMed Central and take full advantage of:}

- Convenient online submission

- Thorough peer review

- No space constraints or color figure charges

- Immediate publication on acceptance

- Inclusion in PubMed, CAS, Scopus and Google Scholar

- Research which is freely available for redistribution

Submit your manuscript at www.biomedcentral.com/submit
Ciomed Central 